\title{
Gas phase acetic acid and its qualitative effects on snow crystal morphology and the quasi-liquid layer
}

\author{
T. N. Knepp ${ }^{1}$, T. L. Renkens ${ }^{1}$, and P. B. Shepson ${ }^{1,2,3}$ \\ ${ }^{1}$ Department of Chemistry, Purdue University, 560 Oval Dr., West Lafayette, IN 47907, USA \\ ${ }^{2}$ Department of Earth and Atmospheric Science, Purdue University, 550 Stadium Mall Dr., West Lafayette, IN 47907, USA \\ ${ }^{3}$ Purdue Climate Change Research Center, Purdue University, 503 Northwestern Ave., West Lafayette, IN 47907, USA
}

Received: 31 October 2008 - Published in Atmos. Chem. Phys. Discuss.: 9 January 2009

Revised: 23 September 2009 - Accepted: 23 September 2009 - Published: 16 October 2009

\begin{abstract}
A chamber was constructed within which snow crystals were grown on a string at various temperatures, relative humidities, and acetic acid gas phase mole fractions. The temperature, relative humidity, and acid mole fraction were measured for the first time at the point of crystal growth. Snow crystal morphological transition temperature shifts were recorded as a function of acid mole fraction, and interpreted according to the calculated acid concentration in the crystal's quasi-liquid layer, which is believed to have increased in thickness as a function of acid mole fraction, thereby affecting the crystal's morphology consistent with the hypothesis of Kuroda and Lacmann. Deficiencies in the understanding of the quasi-liquid layer and its role in determining snow crystal morphology are briefly discussed.
\end{abstract}

\section{Introduction}

\subsection{Initial snow crystal studies}

The natural snow crystal is an interestingly complex species whose study is important for understanding natural phenomena such as: light scattering, snow pack density, permeability, albedo, chemical scavenging, avalanche events, and icing inside aircraft engines (Pasztor, 2008). It has been observed by scientists from the days of Keppler (Keppler, 1966) and Descartes (Frank, 1974); however, it was not until the early twentieth century that significant scientific study of these crystals was begun by Ukichiro Nakaya (Nakaya, 1954). Nakaya was the first to study the influence of temperature and water supersaturation on the morphology of snow crystals (Fig. 1). He collected snow crystals on top of Mount

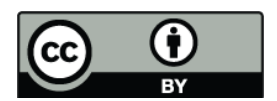

Correspondence to: P. B. Shepson (pshepson@purdue.edu)
Tokachi, Japan, and organized them according to ambient humidity and temperature (Nakaya, 1954). He later grew his own crystals on rabbit hair within a chamber, again measuring the humidity and temperature within the chamber, though not at the point of crystal growth. Similar experiments have been conducted over the past seventy years involving diffusion modeling (Libbrecht, 2005a) and estimation methods (Hallett and Mason, 1958a; Kobayashi, 1961) to determine humidity at the point of crystal growth. However, such methods are problematic due to the chamber's steep temperature and humidity gradients. These parameters do not necessarily change linearly throughout the chamber (see Fig. 2), and can vary from day to day at a single point, making repeated measurement necessary. In past studies non-clean air, such as room air, or air doped with acids (Libbrecht, 2001, 2005b; Libbrecht et al., 2002), alcohols (Anderson et al., 1969), or other organic species (Anderson et al., 1969; Libbrecht et al., 2002), were used in crystal growth chambers. To date, there has been no quantitative measurement of these species, or humidity, at the point of crystal growth, and their relationship to crystal morphology.

\subsection{QLL influence}

Significant work has been done to better understand the underlying physics of morphological transitions, crystal structure, and the role of the quasi-liquid layer (QLL) on ice. The QLL is a thin layer of relatively disordered water on the surface, and grain boundaries (Vrbka and Jungwirth, 2006) of ice, commonly known to make ice slippery (Rosenberg, 2005). For pure water ice, the QLL is believed to be caused by the decrease of surrounding molecules to which the surface water molecules would hydrogen bond, inducing a molecular anharmonicity (Fukuta, 1987; Furukawa and Nada, 1997; Nada and Furukawa, 1997b, a; Wettlaufer, 2001) thereby allowing this thin layer of water to exist below

Published by Copernicus Publications on behalf of the European Geosciences Union. 


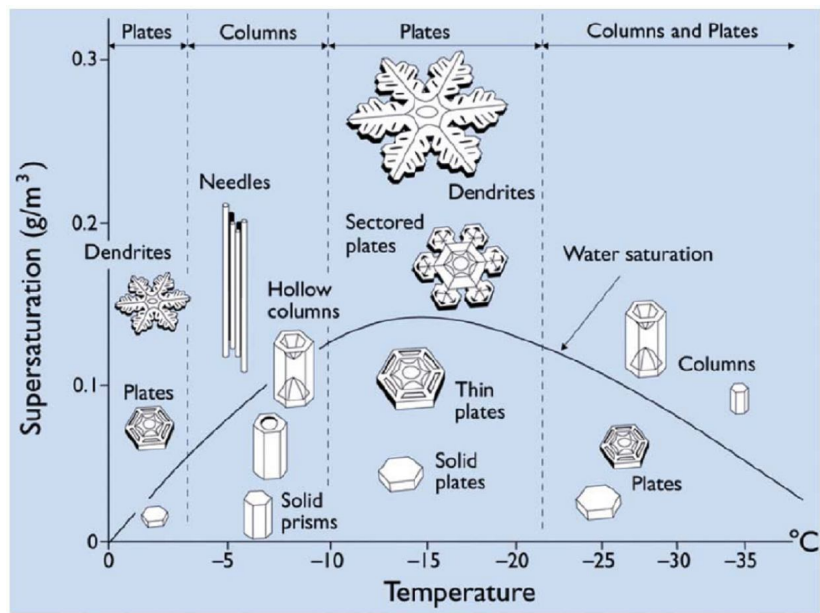

Fig. 1. Original morphology diagram displaying crystal morphology as a function of temperature and water supersaturation as presented by Nakaya (Libbrecht, 2005b); reprinted with permission from Institute of Physics Publisher.

water's theoretical melting point (Makkonen, 1997). For example, Fig. 3 shows the results of a molecular dynamics simulation for the QLL in pure water ice. Though the thickness of the QLL at various temperatures, and its temperature of onset, remain debatable (Bluhm et al., 2002; Sadtchenko and Ewing, 2002), it is well known that the thickness decreases with decreasing temperature (Sadtchenko and Ewing, 2002; Wei and Shen, 2002; Sadtchenko and Ewing, 2003; Ewing, 2004; Voss et al., 2005), differs depending on the ice crystal's facet (Kuroda and Lacmann, 1982; Furukawa et al., 1987a, b; Nada and Furukawa, 1996, 1997a; Furukawa, 1997; Carignano et al., 2005), and is highly dependent on the technique used (Wettlaufer, 1999; Sadtchenko and Ewing, 2002). These differences in QLL thickness, and the physical shape of the crystal, cause different rates of crystal facet growth and thereby change the crystal's morphology as a function of temperature (Kuroda and Lacmann, 1982; Carignano et al., 2005; Libbrecht, 2005b). It is hypothesized that the equilibrium vapor pressure of water above the QLL differs from that over ice, and the vapor pressure will change as a function of solute concentration, and crystal facet. An exhaustive review regarding the physics of ice crystal growth has recently been published by Libbrecht (2005b).

\subsection{Atmospheric implications}

During polar sunrise (March in the Arctic) an interesting series of reactions occurs resulting in total destruction of tropospheric/boundary layer ozone (Barrie et al., 1988) by a heterogeneous catalytic reaction involving bromine free radicals (Finlayson-Pitts et al., 1990; De Haan et al., 1999; Hönninger and Platt, 2002; Finlayson-Pitts, 2003). It is believed that an acidic surface must be available for the initiation and propa-

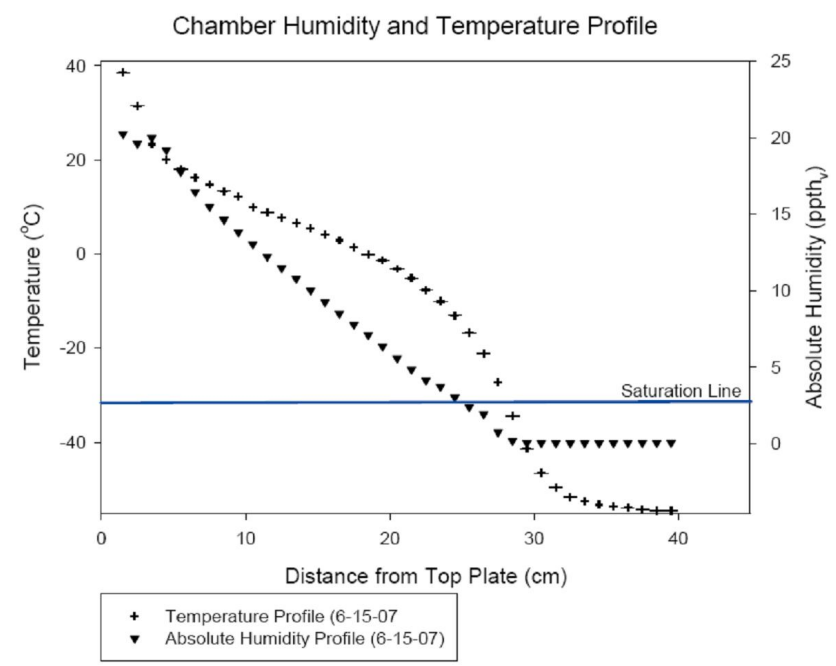

Fig. 2. Humidity and temperature profiles for the chamber. It can be seen how these parameters change in a non-linear fashion within the chamber.

gation of this catalytic reaction (Fan and Jacob, 1992; Abbatt, 1994; Finlayson-Pitts, 2003). Initially, it was believed that frost flowers, highly saline hoar frost crystals that form on newly frozen sea-ice (Perovich and Richter-Menge, 1994), provided this surface as they were believed to have an extremely large specific surface area (Rankin and Wolff, 2002). However, evidence has shown this to not be the case (Dominé et al., 2005), with recent research focusing on the snowpack (Dominé et al., 2005; Simpson et al., 2005) and first year sea ice (Jones et al., 2006; Simpson et al., 2007) as the potential reaction surface to catalyze the activation of bromine. Clearly, a better understanding of the snow crystal's surface will further elucidate its role in ozone depletion events, and allow explicit modeling of these processes.

\subsection{Current work}

To date, the hypothesis that QLL thickness and crystal morphology are interlinked has not been experimentally tested, to the best of our knowledge. It has been shown, in pure water ice, that a distinct morphology transition around $-10^{\circ} \mathrm{C}$ occurs, with some evidence for the QLL disappearing near the same temperature (Kuroda and Lacmann, 1982; Sadtchenko and Ewing, 2002, 2003). It is well known that addition of an ionizable solute will decrease the melting point of the solvent relative to its pure state. It is proposed that by introducing varying amounts of gaseous acetic acid (AA) into a crystal growth chamber the AA uptake into the growing crystal will alter the QLL thickness in a controlled manner (Wettlaufer, 1999; Cho et al., 2002; Voss et al., 2005; McNeill et al., 2006), allowing observation of changes in morphology transition temperatures. Any shift in transition temperature, as a function of AA mole fraction, could thus be 


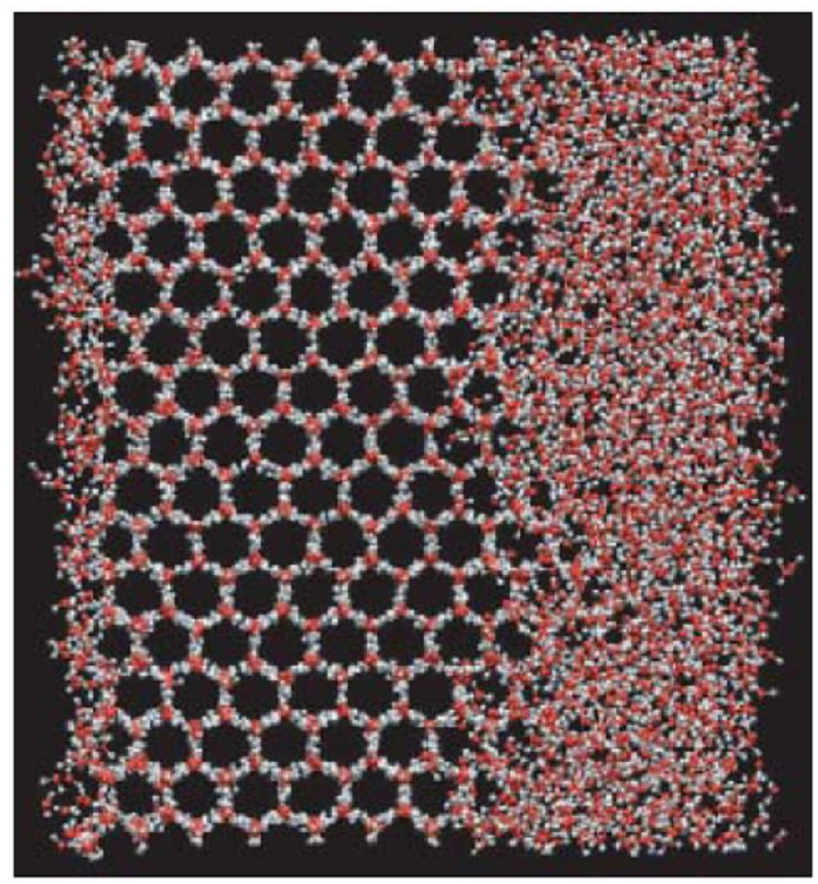

Fig. 3. Molecular dynamics simulation representation of the quasiliquid layer on a freezing ice/water mixture. The QLL can be seen on the left side of the solid (Carignano et al., 2005); reprinted with permission from Taylor and Francis Publishers.

associated with a change in QLL thickness. Conversely, the absence of such an observation could suggest the QLL does not play a role in morphological transitions. Acetic acid was chosen as a starting point, as it is present in the atmosphere, and as Libbrecht (1999) has had success in growing snow crystals with this chemical present. The observed variations in snow crystal morphology with varying humidity, AA mole fraction, and temperature, measured at the point of crystal growth, are presented herein.

\section{Experimental procedure}

\subsection{Chamber design}

A snow crystal growth chamber was constructed after the design of Libbrecht (Libbrecht, 1999) and is shown schematically in Fig. 4. Briefly, the multi-walled chamber sides were constructed of $6 \mathrm{~mm}$ Plexiglass with each Plexiglass layer separated by $2.54 \mathrm{~cm}$ of Styrofoam insulation. The bottom and top plates were $3.8 \mathrm{~cm}$ thick aluminum blocks with the bottom plate channeled to allow flow of coolant (SylthermXLT). Both plates had type K thermocouples embedded to allow measurement of the temperature of each. Two sets of fins project from the bottom plate perpendicular to the plane of the plate. One set extended inside the innermost Plexiglass chamber where crystals grew, with the other surrounded by

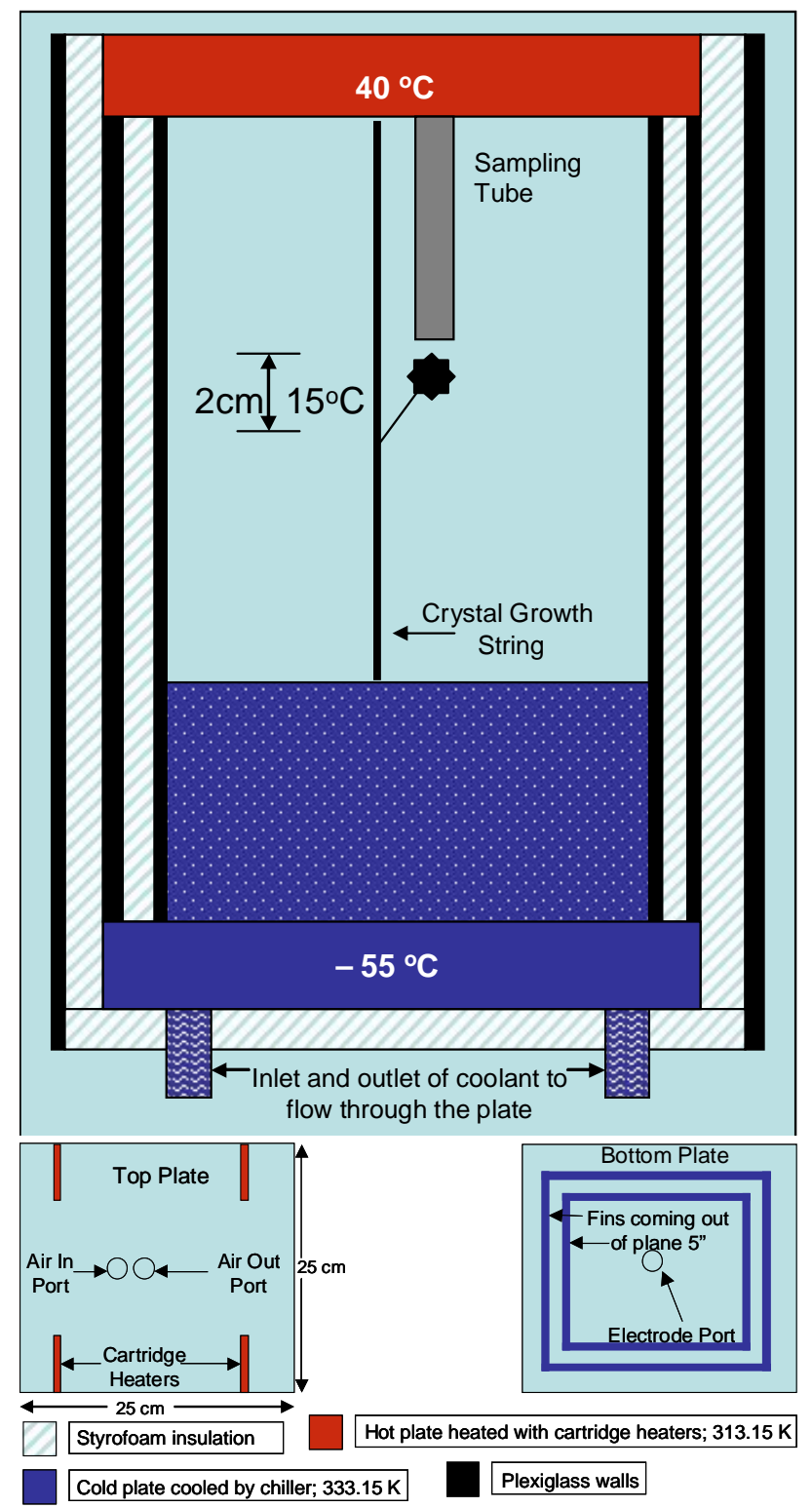

Fig. 4. Crystal chamber schematic as used in the experiment.

a layer of insulation. Both sets of fins aided in the establishment of a steep temperature gradient which is required for crystal growth (Libbrecht, 2005a). The top plate was heated to $40^{\circ} \mathrm{C}( \pm 0.1$; controlled via Omega micro-controller) to help establish the temperature gradient, limit condensation, and to eliminate any influence of varying room temperature. The chamber was sealed from the outside with Permatex RTV clear silicon adhesive, while clean air continuously flowed into the chamber.

A Neslab ULT-80DD recirculating chiller was retrofitted with an Omega micro-controller for increased bath temperature stability. The coolant was flowed through the chamber's bottom plate at $10 \mathrm{~L} / \mathrm{min}$ to ensure equal cooling across 


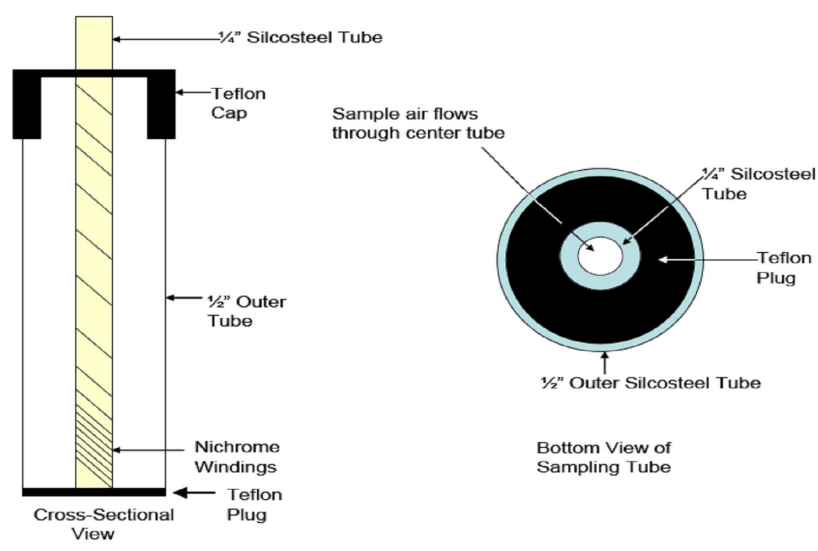

Fig. 5. Schematic representation of the sampling probe. The probe was inserted for sampling and removed afterward.

the plate at a set point temperature of $-56^{\circ} \mathrm{C}(+0.7,-0.2)$. Though the bath temperature fluctuated relatively widely, it had little impact on the chamber's internal temperature $\left( \pm 0.05^{\circ} \mathrm{C}\right)$.

In the initial experiments snow crystals were grown, using Libbrecht's method (Libbrecht, 2005b), on the tip of an electrode inserted through the bottom plate with a potential of $+2000 \mathrm{~V}$ allowing one crystal to grow at a time. To expedite data acquisition the majority of crystals were grown on a string (33\% mercerized cotton, $67 \%$ polyester) hanging vertically through the center of the chamber to enable crystal growth at several temperatures and relative humidities at once, as previously described (Hallett and Mason, 1958a; Hiramatsu and Sturm, 2005). The crystals were illuminated by a halogen lamp through a $2.5 \mathrm{~cm}$ wide slit in the insulation running the whole height of the chamber, and were photographed through another slit of the same dimensions using a Nikon Coolpix 5400 digital camera.

\subsection{Water and AA vapor sources}

Water vapor was input to the chamber by flowing clean air (350 mL/min; MKS 1179) from a Whatman Clean Air Generator (CAG; 74-5041) through a temperature controlled bubbler containing a saturated potassium sulfate (J. T. Baker; A.C.S. Reagent Grade) solution in Millipore water. The bubbler was temperature controlled by a Neslab RTE 5B recirculating chiller pumping an ethylene glycol/water solution (70/30 by volume) through a jacket surrounding the bubbler to maintain a temperature of $25.5( \pm 0.05)^{\circ} \mathrm{C}$. The potassium sulfate was used before we started using the temperature controlled bubbler system, to prevent the bubbler air from being saturated at a given room temperature, which would allow water to condense in transfer lines. However, the salt was allowed to remain in the bubbler for consistency. Experiments were conducted without the salt (i.e. Millipore water) with no observable deviation between the two sets of conditions.
The AA source was a certified Dynacal Permeation Device in a VICI Metronics Dynacalibrator 190 permeation oven set to $32.0^{\circ} \mathrm{C}$ (inlet concentration of $0.9 \mathrm{ppm} \pm 0.03$ at $60 \mathrm{~mL} / \mathrm{min}$; MKS 1179$), 40.0^{\circ} \mathrm{C}(3.2 \mathrm{ppm} \pm 0.64)$, and $60.0^{\circ} \mathrm{C}(4.8 \mathrm{ppm} \pm 0.29)$ depending on the desired gas phase acid mole fraction. The AA source was connected to the clean humid air source outside the top plate via a quarter inch stainless steel tee. Though the moles of AA introduced in the chamber were flow rate independent, a constant flow rate was maintained throughout the experiments. For clean air experiments the chamber was disassembled and washed with $2 \mathrm{M}$ sodium hydroxide (Mallinckrodt AR), rinsed with Millipore water, and reassembled without the permeation oven connected to the humid air input.

\subsection{Snow crystal measurements}

Temperature was measured by inserting a $6 \mathrm{~mm}$ Teflon tube, with a $1.5 \mathrm{~mm}$ type $\mathrm{K}$ thermocouple inside it that extended $5 \mathrm{~cm}$ from the end of the Teflon, to the point of crystal growth. Absolute humidity measurements were initially recorded using a $\mathrm{Li}-\mathrm{COR} 7000 \mathrm{CO}_{2} /$ water analyzer and later using a Vaisala HMT 330 humidity sensor. The two instruments agreed to within $\pm 5 \%(\mathrm{RH})$ at $0^{\circ} \mathrm{C}$. The Vaisala instrument's relative humidity error was measured using a series of dilutions of $100 \% \mathrm{RH}$ air from a bubbler to achieve $100 \% \mathrm{RH}$ levels at various temperatures. The RH offset was observed to increase with decreasing temperature, by $-0.5 \%$ at $0^{\circ} \mathrm{C}$ to $+40 \%$ at $-50^{\circ} \mathrm{C}$. Therefore, these values $(-0.5 \%$ and $40 \%)$ are taken as maximum uncertainty limits in $\mathrm{RH}$ units.

A $13 \mathrm{~mm}$ diameter silco-steel sampling tube was inserted to the point of crystal growth with the external end connected to a mass flow controller and pump to sample air from the chamber at a flow rate comparable to the flow rate into the chamber. The sampling tube (Fig. 5) had a $6 \mathrm{~mm}$ silco-steel tube wrapped in nichrome wire inside it, with both ends of the larger tube capped with Teflon plugs to force air through the $6 \mathrm{~mm}$ tube. The nichrome wire, insulated with glass tape, was used as a resistive heater to heat the inner tube $\left(8^{\circ} \mathrm{C}\right.$; controlled via Omega micro-controller) above ambient temperature to prevent condensation on the inner walls. Humidity was measured, with both sensors, in units of parts per thousand by volume $\left(\mathrm{ppth}_{v}\right)$ and converted to relative humidity, with respect to ice (CRC, 2007), according to the temperature at the point of measurement. All silco-steel was sylonized (Silon CT, Supelco) to limit adsorption.

Acetic acid samples were acquired in a manner similar to those for humidity. Sample air was directed into a series of two impingers each containing $5 \mathrm{~mL}$ of $\approx 1 \times 10^{-5} \mathrm{M}$ potassium bicarbonate (Mallinckrodt, A.C.S. Grade). Typical flow rates and sample times were $120 \mathrm{~mL} / \mathrm{min}$ (MKS 1179) and 60 min, respectively, yielding $>95 \%$ collection efficiency per impinger (as determined using the acetic acid permeation source). The mass of individual impingers with base solution, before and after sample collection, was recorded using 


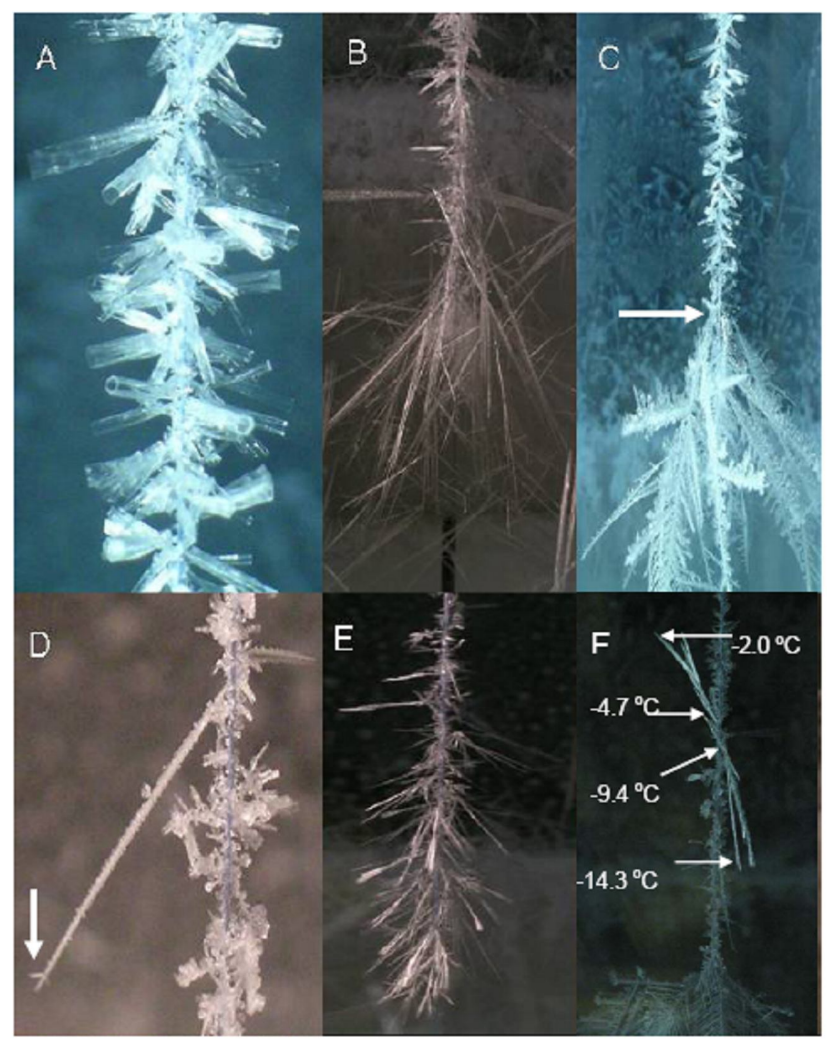

Fig. 6. Pictures of needle-like crystals grown in our chamber, all on a string. Panel (A) shows hollow needles that were common in the -7 to $-15^{\circ} \mathrm{C}$ range. Panel (B) shows the long needle growth that can occur given long growth times $(>12 \mathrm{~h})$. Panel $(\mathbf{C})$ shows the distinct transition from needles to dendrites (indicated by arrow). (D) shows a needle that has grown through a transition temperature and has started to grow dendritically at its tip. Panels (E) and (F) show crystals grown in clean air; note the lack of transitions over the entire range $\left(0\right.$ to $\left.-25^{\circ} \mathrm{C}\right)$. It can be seen in $(\mathrm{F})$ that crystals growing through Nakaya's transition temperature display no morphological change. However, dendrites at cold temperatures $\left(-25^{\circ} \mathrm{C}\right)$ were observed.

a Mettler Toledo AG245 analytical balance to determine the final mass of water. A density of $1.0 \mathrm{~g} / \mathrm{mL}$ for the solution was assumed, and from the calculated solution masses the final solution volume was calculated and used for determination of acetate concentration in solution (typically on the order of $\approx 1 \times 10^{-5} \mathrm{M}$ for the first impinger, and $\approx 1 \times 10^{-7}$ for the second), and gas phase mole fraction. The mass added due to acetic acid collection in the liquid phase is on the order of $0.1-10 \mu \mathrm{g}$, thus not introducing a significant change to the impinger's total mass. The samples were transferred to $0.5 \mathrm{~mL}$ Polyvial cuvettes, sealed with filter caps, and stored in a freezer at $-45.0^{\circ} \mathrm{C}$ until analysis. The acetate concentration was not observed to change as a function of time in the freezer. Experiments were conducted to determine the amount of carryover (desorbing analyte on sample lines from previous samples) between samples; the carryover was below the instrument's limit of detection.

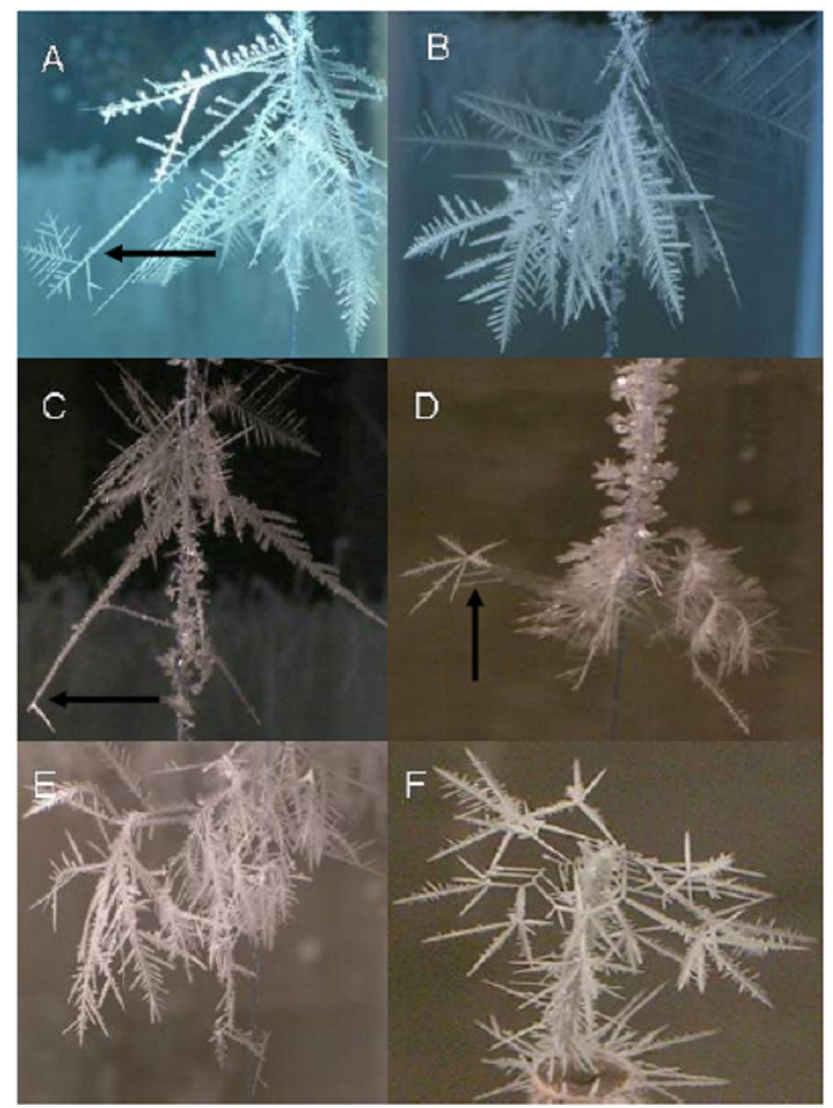

Fig. 7. Pictures of dendritic crystals grown in the chamber in presence of AA. Crystals in panels (A-E) were grown on string, (F) was grown on the electrode. In (A), (C), and (D) morphology changes due to the growing crystal crossing a transition temperature are seen.

The concentration of acetate in the samples was determined using a Dionex DX500 ion chromatograph with an ED40 detector, AS9-HC column, and AG9-HC guard column. A $3.5 \mathrm{mM}$ carbonate/bicarbonate eluent $(1: 1,1 \mathrm{~mL} / \mathrm{min}$ flow rate) was used, yielding typical acetate ion peak retention times of five minutes. Eluent was prepared from sodium carbonate and sodium bicarbonate (Mallinckrodt, A.C.S. Grade), weighed on the analytical balance and dissolved in Millipore water $(<18 \mathrm{M} \Omega)$ filtered through a filtering support pad (Dionex AP10037x) in a Fisher Büchner funnel. As aerosol from the bubbler solution may be a potential source of contamination, the chamber air was tested for sulfate. No sulfate was observed in the chromatograms.

Acetate standards were prepared using sodium acetate (Sigma-Aldrich, A.C.S. Grade), dried at $200^{\circ} \mathrm{C}$ for two weeks in an oven purged with dry clean air, weighed on the analytical balance and diluted in Millipore water. Peak areas were integrated using the Dionex software. 


\subsection{Air quality measurements}

Additional analysis of clean air conditions was done after observing what appeared to be a unique morphology present under these conditions. The chamber was cleaned (vide supra) and allowed to flush with Ultra-Zero air (Matheson; hydrocarbon trap scrubbed) for one month as in previous clean air experiments that used CAG air. The clean air samples were analyzed using: a Thermo-Finnigan 5890 GC with a DB-1 column for hydrocarbon analysis, a TSI 3080 Electrostatic Classifier with a 3775 Condensation Particle Counter for aerosol measurements, and a total reactive nitrogen analyzer for $\mathrm{NO}_{\mathrm{x}}$ and $\mathrm{NO}_{\mathrm{y}}$. Hydrocarbon measurements of chamber air were included as there is evidence to suggest they can influence the QLL thickness (Bluhm et al., 2002). Though Bluhm et al. (2002) were not able to conclusively distinguish between the influence of aliphatic hydrocarbons and organic acids, hydrocarbon content is presented herein for completeness.

\section{Results and discussion}

\subsection{General}

Snow crystals were grown on the tip of an electrode, and on a string hanging vertically through the chamber. Growing crystals on a string provided the distinct advantage of displaying a spatial gradient of conditions enabling the determination of transition temperatures. Sample photographs of the snow crystals are shown in Figs. 6 and 7. Interestingly, in our initial experiments no temperature dependent morphological diversity was observed in clean air experiments, for which all crystals were filament-like needles (Fig. 6e, f). We have since tried to reproduce these results to analyze the air to gain a better understanding of the conditions required to obtain this unique morphology. However, we have not been able to reproduce this observation. Conversely, in the presence of AA different morphologies were consistently and reproducibly observed as a function of temperature and relative humidity, with transition temperatures changing with AA mole fraction. These observations are presented in detail in Sect. 3.2.

Transition temperatures between morphological types were determined by one of two methods. First, if long needle-like crystals grew to some extent in the vertical direction they may cross a transition temperature and change their morphology (Figs. 6d; 7a, c, d). Second, if no crystals grew in the vertical direction the transition temperature was estimated according to the temperature at which the individual crystals' morphology on the string changes (Fig. 6c). Throughout the study the predominant morphologies observed were dendrites, needles, plates, and hollow columns. The humidities present in the chamber typically exceeded $150 \%$, with respect to ice. It is important to note that such a high humidity does not affect the morphology of the crystals at these relatively high temperatures, but does tend to make them more dendritic, as indicated in Fig. 1 (Kuroda and Lacmann, 1982).

It was generally observed that crystals grew faster at lower temperatures. This is expected (Libbrecht, 2005b) as the degree of supersaturation increased exponentially with decreasing temperature (Fig. 2) due to the constant flow of warm humid air into the top of the chamber, with some degree of turbulent mixing in the vertical direction. The rate of crystal growth increases with the square root of supersaturation as represented in Eq. (1) (Libbrecht, 2005b) where $v_{n}$ is growth rate $(\mathrm{m} / \mathrm{s}), \alpha$ is the dimensionless condensation coefficient, $c_{\mathrm{sat}}$ is the equilibrium number density over an ice surface (molecules $\left./ \mathrm{cm}^{3}\right), c_{\text {solid }}$ is the number density for ice (molecules $/ \mathrm{cm}^{3}$ ), $k$ is Boltzmann's constant, $T$ is temperature in Kelvin, $m$ is mass of one water molecule $(\mathrm{kg})$, and $\sigma_{\text {surf }}$ is supersaturation (dimensionless) directly over the growing ice surface.

$v_{n}=\alpha \cdot \frac{c_{\text {sat }}}{c_{\text {solid }}} \sqrt{\frac{k T \sigma_{\text {surf }}}{2 \pi m}}$

\subsection{Dependence of morphology on AA concentration}

It is interesting to note that similar morphologies were consistently observed for all AA mole fractions except for the clean air samples (Fig. 6e, f). In the clean air samples, during initial experiments, there was a uniform, temperature independent, morphology that covered the entire temperature range (down to $-25^{\circ} \mathrm{C}$ ). Given longer growth times (e.g. 12 $24 \mathrm{~h}$ ) these crystals began to be clustered making any observation of morphological transitions difficult; however, from the shorter growth time experiments, and from observation of crystals growing through the temperature where a morphology change should occur, but does not (Fig. 6e, f), we concluded that under these conditions morphological diversity was not present. These observations were reproducible during the first two clean air experiment sessions (lasting 2-3 weeks each, separated by AA doped experiments lasting 2-3 weeks each, using air from the CAG); however, we have since not been able to reproduce these results under the same conditions as before, using either hydrocarbon scrubbed Ultra-zero air, or CAG air. We conclude that there exists some set of conditions in which the crystals take a uniform morphology independent of temperature, but we are not able to define those conditions in gas-phase composition terms. After flushing the chamber with Ultra-Zero Air for one month, the hydrocarbon content in the chamber during our clean air experiments was $<65 \%$ that of room air, the mean aerosol number density was $<80 / \mathrm{cm}^{3}(<1 \%$ of the room air's aerosol number density), the $\mathrm{NO}_{2}$ levels were all below the instrument's detection level ( $20 \mathrm{ppt})$ while NO had a mole fraction of 570 ppt. From these additional experiments we can say that the chamber air is much cleaner than room/outdoor air which was used in previous studies (Nakaya, 1954; Magono et al., 1962; Libbrecht, 2001; 

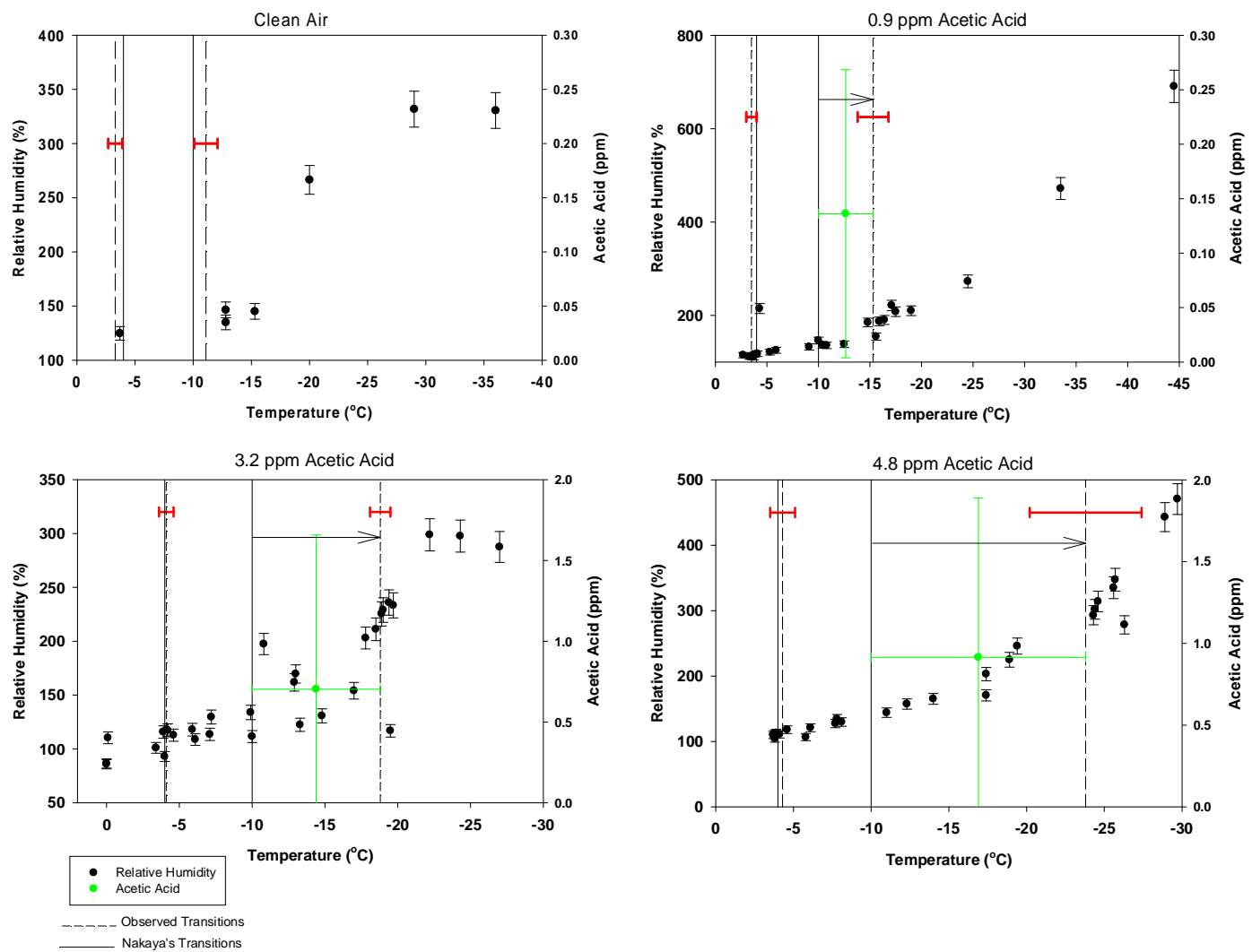

Fig. 8. Morphology diagrams from the various AA mixing ratio experiments with the acid mixing ratio that is introduced into the chamber (remains constant throughout specified experiment) indicated by each graph's title. The previously measured transition temperatures from Nakaya and others, who did not measure air impurity levels or humidity at the point of crystal growth, are represented by the solid vertical line, with our observed shifted transition temperatures represented by the dashed lines. Error bars illustrate the standard deviation of the measurement (minimum 5 data points). Horizontal error bars for data points are omitted due to their small value $\left( \pm 0.05^{\circ} \mathrm{C}\right)$. The average acetic acid mole fraction measured at the point of the crystals grown between Nakaya's transition and those observed in the present study are represented by the green points. Acetic acid uncertainties (vertical bars) are the measured variability of the measurement of the experiment; the horizontal bars indicate the temperature range over which the average was calculated.

Libbrecht and Yu, 2001; Hiramatsu and Sturm, 2005), or air from an unspecified source (Hallett and Mason, 1958b; Kobayashi, 1958, 1961, 1965; Takahashi and Mori, 2006). We are unable to find a previous report of this distinct paucity of morphological diversity for snow crystals grown in clean air.

It is assumed that the acid partitions to the surface of the growing crystal, is solvated, is partially ionized, and that it (whether ionized or neutral) exists entirely or largely within the surface layers, or the QLL of the crystal (Cho et al., 2002; Grannas et al., 2007a, b). The presence of the AA must then increase the QLL thickness for all temperatures, as well as enable it to exist below $-10^{\circ} \mathrm{C}$, the temperature proposed to represent a minimum (though the temperature of onset of the QLL remains highly debated in the literature), below which the QLL has been proposed to not exist for pure water ice (Kuroda and Lacmann, 1982; Dosch et al., 1995; Sadtchenko and Ewing, 2002). Our hypothesis is that this should cause shifts in the morphological transitions, if the QLL presence or composition affects the values of $\alpha$ or $c_{\text {sat }}$. Figure 8 shows the morphology diagram constructed from this study. This figure shows humidity and AA measurements as measured at the point of crystal growth, with the AA measurements represented by the average mole fraction over the temperature range specified by the horizontal error bar. Interpretation of the AA data is made difficult due to the reproducibility of the AA measurement in the experiment $( \pm 45 \%)$, the combination of turbulent mixing in the chamber, and the continual exchange with the chamber walls (which quickly become ice coated) and crystals. However, differences in average acid mole fraction between the clean air, and AA doped air experiments are readily observed, in addition to a slight trend of decreasing mole fraction in the chamber with decreasing chamber temperature, related to the increasing partitioning to the ice or the walls at low temperatures due to an exponential decrease in the acid's vapor pressure (Stull, 1947; Potter and Ritter, 1954; CRC, 2007). It is important to note that as the mole fraction of AA entering the chamber is increased, 
Table 1. Data used for determination of concentration of acid in the QLL. Temperatures in parentheses are previously observed transition temperatures from Nakaya's work, partially represented in Fig. 1.

\begin{tabular}{ccc}
\hline $\begin{array}{c}\text { Gas phase } \\
\text { inlet conc. } \\
(\mathrm{ppm})\end{array}$ & $\begin{array}{c}\text { Observed } \\
\text { Transition T } \\
\left({ }^{\circ} \mathrm{C}\right)\end{array}$ & $\begin{array}{c}\text { Acid } \\
\text { Concentration } \\
(\mathrm{M})\end{array}$ \\
\hline 0.9 & $-15.3(-10)$ & 3.70 \\
3.2 & $-18.8(-10)$ & 4.53 \\
4.8 & $-23.8(-10)$ & 5.71 \\
\hline
\end{tabular}

the measured AA mole fraction at the point of crystal growth does not necessarily increase proportionately, for example, due to increased uptake. However, what is important is the concentration in the condensed phase. While the measured gas phase concentrations for the $3.2 \mathrm{ppm}$ experiment was not several times larger than for the $0.9 \mathrm{ppm}$ case, this fact must mean that the AA that is not observed in the gas phase has undergone uptake into the condensed phase, i.e. into the crystals.

There are two distinctly different impacts of AA concentration in the chamber: the transition from dendrites/plates to needles at $-4^{\circ} \mathrm{C}$ is not impacted, while the lower temperature transition from needles to dendrites occurs at progressively lower temperatures as the AA concentration increases (Fig. 8). Specifically, transitions from needles to dendrites, previously reported at $-10^{\circ} \mathrm{C}$, were observed to be shifted to colder temperatures: $-15.3^{\circ} \mathrm{C},-18.8^{\circ} \mathrm{C}$, and $-23.8^{\circ} \mathrm{C}$, for the $0.9 \mathrm{ppm}, 3.2 \mathrm{ppm}, 4.8 \mathrm{ppm}$ conditions, respectively. This is interpreted as an indication that the QLL thickness influences the crystal morphology by influencing facet growth rates, as previously discussed (Kuroda and Lacmann, 1982; Libbrecht, 2005b). As compared to Nakaya's diagram, the morphological transitions are significantly shifted to colder temperatures, when AA is present, by as much as $14^{\circ} \mathrm{C}$ for the $4.8 \mathrm{ppm}$ sample. These observations can be interpreted in the following way: first, the AA concentration has no impact on the high temperature transition from plates to needles, as the QLL has been shown to exist at this temperature via many techniques (Golecki and Jaccard, 1978; Döppenschmidt et al., 1998; Shen, 1998; Döppenschmidt and Butt, 2000; Wei et al., 2001, 2002; Cho et al., 2002; Sadtchenko and Ewing, 2002, 2003; Sadtchenko et al., 2002; Wei and Shen, 2002; Ewing, 2004; Carignano et al., 2005), with a thickness of about $2 \mathrm{~nm}$, or about 5 monolayers for pure water ice (Sadtchenko and Ewing, 2002). For this transition then, it must be that increasing the QLL thickness has no impact on what must occur, i.e. an increasing rate of uptake for water onto the basal facets relative to the prism facets. Second, there must then be a mechanism that drives this transition that is independent of the QLL properties. Carignano et al. (2005) found from a molecular dynamics study that the rate of crystal growth onto the relatively rough prism plane decreases with decreasing temperature. Thus it must be that the uptake rate for the basal plane overtakes that for the prism plane at $-4^{\circ} \mathrm{C}$. Carignano et al. (2005) discuss that growth on the basal plane requires formation of an in-plane cluster before a layer of ice will grow. At these relatively warm temperatures water rotation is more facile, and thus as prism facet growth slows with decreasing temperature, the basal facet growth becomes dominant.

For the lower temperature transition it has been hypothesized that the disappearance of the QLL drives the transition to faster uptake rates onto the prism facets (Kuroda and Lacmann, 1982). Presumably, the accommodation coefficient for water uptake is faster onto the rougher surface at or below the temperature of QLL onset. With increasing AA partial pressure, such a transition would occur at lower temperatures, moving the transition temperature, as observed. In the absence of impurities, at $-10^{\circ} \mathrm{C}$, the surface water molecules become less disordered, and thus less rotationally mobile, and assembly into the planar growth layers becomes slower, and growth onto the rougher prism facet overtakes the rate onto the basal facet. But, with increasing AA, the QLL remains on the basal facet to lower temperatures, delaying the transition to relatively faster growth on the prism plane. Note, the low temperature transition from plates to needles, as seen by Nakaya at $-22^{\circ} \mathrm{C}$, was not observed in this study.

Cho et al. (2002) have shown that the concentration of ions in the QLL is what would be expected based on the associated bulk freezing point depression data (CRC, 2007). Since the QLL is believed to be present for each crystal grown in the presence of AA (down to the second transition temperature), the freezing point depression data for AA can be used, taking the freezing point depression to be the temperature of the crystal relative to $0^{\circ} \mathrm{C}$. Table 1 shows the crystal temperature and calculated QLL AA concentration for each of the AA-dependent transitions.

\subsection{AA uptake and impact on morphology}

The QLL thickness can be calculated, when acetic acid is present under growth conditions, using Eq. (2), where $P_{A}$ is the AA partial pressure in torr, $K_{\text {surf }}$ is the gas to surface partitioning coefficient from Sokolov and Abbott (2002) in molecules $\mathrm{cm}^{-2}$ torr $^{-1},[A]$ is the calculated AA condensed phase concentration (molecules $/ \mathrm{cm}^{3}$ ) from freezing point depression, and $Z_{\mathrm{QLL}}$ is the thickness of the QLL in meters. The uptake and mass accommodation coefficient for AA interaction with ice has been recently studied by Sokolov and Abbatt (2002). Though the data presented in Sokolov and Abbatt (2002) only go up to $245 \mathrm{~K}$, at which point the Langmuir model began to break down, an approximate calculation can still be performed.

$\frac{P_{A} \cdot K_{\text {surf }}}{[A] \cdot 100}=Z_{\mathrm{QLL}}$ 
Using the Van't Hoff plot from Sokolov and Abbatt (2002) the uptake for the $-23.8^{\circ} \mathrm{C}$ transition case from needles to dendrites was calculated to be $3.9 \times 10^{17}$ molecules $/ \mathrm{cm}^{2} /$ torr. The measured AA equilibrium partial pressure for the $-23.8^{\circ} \mathrm{C}$ transition temperature was $\sim 4.6 \times 10^{-4}$ Torr, yielding an estimated uptake of $1.8 \times 10^{14}$ molecules $/ \mathrm{cm}^{2}$. Using the freezing point depression (FPD) concentration for this temperature (CRC, 2007) of $3.4 \times 10^{21}$ molecules $/ \mathrm{cm}^{3}$ yields an estimated QLL thickness of $0.5 \mathrm{~nm}$, or, roughly 1 monolayer $(0.4 \mathrm{~nm} /$ monolayer $)$. This may be the approximate thickness limit at which the morphological transition occurs. At warmer temperatures inside the chamber (i.e. nearer the top plate), the AA concentration increases, and the uptake rate decreases, yielding an approximate constant thickness to near $-10^{\circ} \mathrm{C}$ of 1 monolayer. We note that it is well known that $\mathrm{CH}_{3} \mathrm{COOH}$ can dimerize at high concentrations/low temperatures (Orlando and Tyndall, 2003). However, for $-23.8^{\circ} \mathrm{C}$ and the observed gas phase concentrations, the fraction of dimers in our system is $\sim 0.01 \%$.

\subsection{Acetic acid/water interactions}

It is instructive to understand how the AA molecule interacts with water on a molecular level, in/with the QLL. The acid dissociation constant in water is $1.7 \times 10^{-5}$, and is likely different in the QLL (Dominé and Rauzy, 2004). Thus, for the acid concentrations typical for the QLL in these experiments, AA is only $\sim 0.2 \%$ dissociated, or less. Thus, the impact of adsorbed/dissolved AA on the surface water is mostly due to the neutral acid. Previous gas phase theoretical work has shown that water strongly hydrogen bonds with AA (Aloisio and Francisco, 2000), with bond strengths ranging from $11-14 \mathrm{kcal} / \mathrm{mol}$. Such a bond strength is impressive as it exceeds those formed by stronger acids (e.g. nitric acid, $7.2 \mathrm{kcal} / \mathrm{mol}$; Aloisio and Francisco, 2000). More importantly, it is greater than the strength of the hydrogen bonds between water molecules $(5.58 \mathrm{kcal} / \mathrm{mole}$; Suresh and Naik, 2000). In this way, AA likely interacts with and extends the thickness of the QLL. Unpublished NMR studies in this group regarding AA in ice show that a substantial fraction of AA is indeed in the QLL for the temperature range studied here. Acetic acid is capable of hydrogen bonding wherever it has a lone pair of electrons on an oxygen atom. The carbonyl oxygen will bond to two waters (one of which forms a cyclic arrangement between a hydrogen and the carbonyl oxygen, and the water's oxygen and the acidic hydrogen) while the acidic oxygen bonds with two waters yielding an $\mathrm{Ac}\left(\mathrm{H}_{2} \mathrm{O}\right)_{4}$ structure (Francisco, 2008).

The AA is expected to remain in the QLL because of its size, polarizability (Jungwirth and Tobias, 2000, 2001, 2002, 2006; Cho et al., 2002; Byrk and Haymet, 2004; Liu et al., 2004; Gopalakrishnan et al., 2005; Mucha et al., 2005; Petersen et al., 2005; Carignano et al., 2007), and its hydrophobic methyl group, regardless of whether or not it has deprotonated. This will yield a high concentration of AA in the surface layer thereby inducing surface anharmonicity (Fukuta, 1987; Furukawa and Nada, 1997; Nada and Furukawa, 1997b, a; Wettlaufer, 2001), which will further increase the surface's ability to scavenge AA from the gas phase at temperatures below which the QLL would normally not exist (McNeill et al., 2006). How molecules such as AA impact surface properties is likely important to morphological transitions in the real atmosphere, where a wide array of polar species, e.g. carboxylic acids (Kawamura et al., 2001), can undergo uptake and influence the surface properties. It is clear then that study of water uptake onto growing snow crystals in the presence of co-adsorbers should be a priority for this area of inquiry, which is still in its infancy.

\section{Conclusions}

Acetic acid and humidity at the point of snow crystal growth were measured for the first time. It was observed that the presence of AA has a profound impact on the transition from needles to dendrites, previously reported to occur at $-10^{\circ} \mathrm{C}$, with the transition occurring at progressively lower temperatures as the gas phase AA concentration increases. It was shown that as the acid mole fraction increased the transition temperatures shifted to colder temperatures, by as much as $14^{\circ} \mathrm{C}$. In contrast, AA has no impact on the warmer temperature transition from plates to needles. We interpret this as related to the impact of AA on the presence of a quasiliquid layer, which then impacts the relative rates of water uptake on the two crystal facets, due to the very different growth mechanisms on the two facets (Carignano et al., 2005). This seems to be in support of Kuroda and Lacmann's hypothesis that the QLL thickness plays a role in the crystal's morphology (Kuroda and Lacmann, 1982; Libbrecht, 2005b). Based on our rough calculations, we propose that a QLL thickness of only one monolayer is sufficient to impact this morphological transition. That implies that the surface structure/composition is critical for determining snow crystal morphology. Given that snow precipitation occurs within a chemically complex medium, and that it is believed that even organic adsorbates exist within the surface layer (Grannas et al., 2007a), the presence, nature, and concentration of such adsorbates may well affect snow crystal morphology, particularly for polluted air masses. This impact should clearly be studied further.

The conclusions that can be drawn from this research are observational, and limited by the lack of observational understanding of the snow crystal's surface physics, and the lack of understanding of the QLL. The QLL has proven difficult to characterize, even on the most basic level of determining its thickness at various temperatures (Golecki and Jaccard, 1978; Döppenschmidt and Butt, 2000; Sadtchenko and Ewing, 2002; Wei et al., 2002; Wei and Shen, 2002). Given that most bulk water thermodynamic values are non-transferable to the QLL (Dominé and Rauzy, 2004) significant work 
regarding the physical and chemical nature of this phase must be done to appropriately understand the snow crystal's surface physics and chemistry.

The QLL remains an enigmatic, yet highly important, part of surface chemistry, regarding which much has been learned, though much yet needs to be done to attain a greater understanding of the physics of the snow crystal. Though there have been significant amounts of research conducted to better understand this phase there remains an extreme paucity of understanding in several respects. Herein was reported the effects of one acid on the morphology, and by association the QLL, while in the atmosphere snow crystals encounter myriad other chemical species, the effects of which are not currently understood. One can wonder whether Nakaya, a nuclear physicist sitting on his mountain top some seventy years ago, imagined his study of "nature's letter from the sky" (Furukawa, 1997) would yield such a broad reaching interest as it has.

Acknowledgements. The authors would like to thank especially Joseph Francisco for his helpful discussion; Marjan Alaghmand, Judy Yu, and Nate Slade for air analysis; Robert Santini, Jim Zimmerman and Randy Replogle from the Jonathan Amy Facility for Chemical Instrumentation for the electronic work, chamber plate construction and beneficial discussion; and Ned Gangwer from the Purdue Chemistry Shop for the construction of the Plexiglass chamber. The research described here is based upon work supported by the National Science Foundation under Grant No. OPP-0732556. This is paper number 0714 of the Purdue Climate Change Research Center.

Edited by: V. F. McNeill

\section{References}

Abbatt, J. P. D.: Heterogeneous reaction of $\mathrm{HOBr}$ with $\mathrm{HBr}$ and $\mathrm{HCl}$ on ice surfaces at $229 \mathrm{~K}$, Geophys. Res. Lett., 21, 665-668, 1994.

Aloisio, S. and Francisco, J. S.: New Radical - Molecule Association Compounds, J. Am. Chem. Soc., 122, 9196-9200, 2000.

Anderson, B. J., Sutkoff, J. D., and Hallett, J.: Influence of Methyl 2-Cyanoacrylate Monomer on Habit of Ice Crystals Grown from Vapor, J. Atmos. Sci., 26, 673-674, 1969.

Barrie, L. A., Bottenheim, J. W., Schnell, R. C., Crutzen, P. J., and Rasmussen, R. A.: Ozone destruction and photochemical reactions at polar sunrise in the lower Arctic atmosphere, Nature, 334, 138-141, 1988.

Bluhm, H., Ogletree, D. F., Fadley, C. S., Hussain, Z., and Salmeron, N.: The premelting of ice studied with photoelectron spectroscopy, J. Phys.-Condens. Mat., 14, L227-L233, 2002.

Byrk, T. and Haymet, A. D. J.: Charge separation at the ice/water interface: a molecular dynamics simulation study of solute ions at the ice basal plane, J. Mol. Liq., 112, 47-50, 2004.

Carignano, M. A., Shepson, P. B., and Szleifer, I.: Molecular dynamics simulations of ice growth from supercooled water, Mol. Phys., 103, 2957-2967, 2005.

Carignano, M. A., Shepson, P. B., and Szleifer, I.: Ions at the ice/vapor interface, Chem. Phys. Lett., 436, 99-103, 2007.
Cho, H., Shepson, P. B., Barrie, L. A., Cowin, J. P., and Zaveri, R.: NMR investigation of the quasi-brine layer in ice/brine mixtures, J. Phys. Chem. B, 106, 11226-11232, 2002.

CRC: CRC Handbook of Chemistry and Physics, 87 ed., edited by: Lide, D. R., Taylor \& Francis, Boca Raton, FL, 2007.

De Haan, D. O., Brauers, T., Oum, K., Stutz, J., Nordmeyer, T., and Finlayson-Pitts, B. J.: Heterogeneous chemistry in the troposphere: experimental approaches and applications to the chemistry of sea salt particles, Int. Rev. Phys. Chem., 18, 343-385, 1999.

Domine, F. and Rauzy, C.: Influence of the ice growth rate on the incorporation of gaseous $\mathrm{HCl}$, Atmos. Chem. Phys., 4, 25132519, 2004, http://www.atmos-chem-phys.net/4/2513/2004/.

Dominé, F., Taillandier, A. S., Simpson, W. R., and Severin, K.: Specific surface area, density and microstructure of frost flowers, Geophys. Res. Lett., 32, L13502, doi:10.1029/2005GL023245, 2005.

Döppenschmidt, A., Kappl, M., and Butt, H. J.: Surface properties of ice studied by atomic force microscopy, J. Phys. Chem. B, 102, 7813-7819, 1998.

Döppenschmidt, A. and Butt, H. J.: Measuring the thickness of the liquid-like layer on ice surfaces with atomic force microscopy, Langmuir, 16, 6709-6714, 2000.

Dosch, H., Lied, A., and Bilgram, J. H.: Glancing-Angle X-RayScattering Studies of the Premelting of Ice Surfaces, Surf. Sci., 327, 145-164, 1995.

Ewing, G. E.: Thin film water, J. Phys. Chem. B, 108, 1595315961, 2004.

Fan, S. M. and Jacob, D. J.: Surface Ozone Depletion in Arctic Spring Sustained by Bromine Reactions on Aerosols, Nature, 359, 522-524, 1992.

Finlayson-Pitts, B. J., Livingston, F. E., and Berko, H. N.: Ozone destruction and bromine photochemistry at ground level in the Arctic spring, Nature, 343, 622-625, 1990.

Finlayson-Pitts, B. J.: The tropospheric chemistry of sea salt: A molecular-level view of the chemistry of $\mathrm{NaCl}$ and $\mathrm{NaBr}$, Chem. Rev., 103, 4801-4822, 2003.

Frank, F. C.: Descartes' observations on the Amsterdam snowfalls of 4, 5, 6, and 9 February 1635, J. Glaciol., 13, 535-542, 1974.

Fukuta, N.: An Origin of the Equilibrium Liquid-Like Layer on Ice, J. Phys.-Paris, 48, 503-509, 1987.

Furukawa, Y., Yamamoto, M., and Kuroda, T.: Ellipsometric Study of the Transition Layer on the Surface of an Ice Crystal, J. Cryst. Growth, 82, 665-677, 1987a.

Furukawa, Y., Yamamoto, M., and Kuroda, T.: Ellipsometric Study of the Ice Surface Structure Just Below the Melting Point, J. Phys.-Paris, 48, C1 495-C491 501, 1987b.

Furukawa, Y.: Faszination der Schneekristalle - wie ihre bezaubernden Formen entstehen, Chem. Unserer Zeit, 31, 58-65, 1997.

Furukawa, Y. and Nada, H.: Anisotropic surface melting of an ice crystal and its relationship to growth forms, J. Phys. Chem. B, 101, 6167-6170, 1997.

Golecki, I. and Jaccard, C.: Intrinsic Surface Disorder in Ice near Melting-Point, J. Phys. C Solid State, 11, 4229-4237, 1978.

Gopalakrishnan, S., Jungwirth, P., Tobias, D. J., and Allen, H. C.: Air-liquid interfaces of aqueous solutions containing ammonium and sulfate: Spectroscopic and molecular dynamics studies, J. 
Phys. Chem. B, 109, 8861-8872, 2005.

Grannas, A. M., Bausch, A. R., and Mahanna, K. M.: Enhanced Aqueous Photochemical Reaction Rates after Freezing, J. Phys. Chem. A, 111, 11043-11049, 2007a.

Grannas, A. M., Jones, A. E., Dibb, J., Ammann, M., Anastasio, C., Beine, H. J., Bergin, M., Bottenheim, J., Boxe, C. S., Carver, G., Chen, G., Crawford, J. H., Dominé, F., Frey, M. M., Guzmán, M. I., Heard, D. E., Helmig, D., Hoffmann, M. R., Honrath, R. E., Huey, L. G., Hutterli, M., Jacobi, H. W., Klán, P., Lefer, B., McConnell, J., Plane, J., Sander, R., Savarino, J., Shepson, P. B., Simpson, W. R., Sodeau, J. R., von Glasow, R., Weller, R., Wolff, E. W., and Zhu, T.: An overview of snow photochemistry: evidence, mechanisms and impacts, Atmos. Chem. Phys., 7, 4329-4373, 2007b,

http://www.atmos-chem-phys.net/7/4329/2007/.

Hallett, J. and Mason, B. J.: The Influence of Temperature and Supersaturation on the Habit of Ice Crystals Grown from the Vapour, Proc. R. Soc. Lon. Ser.-A, 247, 440-453, 1958a.

Hallett, J. and Mason, B. J.: The Influence of Temperature and Supersaturation on the Habit of Ice Crystals Grown from the Vapour, Proc. R. Soc. Lon. Ser.-A, 247, 440-453, 1958b.

Hiramatsu, K. and Sturm, M.: A Simple, Inexpensive Chamber for Growing Snow Crystals in the Classroom, The Physics Teacher, 43, 23-25, 2005.

Hönninger, G. and Platt, U.: Observations of $\mathrm{BrO}$ and its vertical distribution during surface ozone depletion at Alert, Atmos. Environ., 36, 2481-2489, 2002.

Jones, A. E., Anderson, P. S., Wolff, E. W., Turner, J., Rankin, A. M., and Colwell, S. R.: A role for newly forming sea ice in springtime polar tropospheric ozone loss? Observational evidence from Halley station, Antarctica, J. Geophys. Res., 111, D08306, doi:10.1029/2005JD006566, 2006.

Jungwirth, P. and Tobias, D. J.: Surface Effects on Aqueous Ionic Solvation: A Molecular Dynamics Simulation Study of $\mathrm{NaCl}$ at the Air/Water Interface from Infinite Dilution to Saturation, J. Phys. Chem. B, 104, 7702-7706, 2000.

Jungwirth, P. and Tobias, D. J.: Molecular Structure of Salt Solutions: A New View of the Interface with Implications for Heterogeneous Atmospheric Chemistry, J. Phys. Chem. B, 105, 1046810472, 2001.

Jungwirth, P. and Tobias, D. J.: Ions at the Air/Water Interface, J. Phys. Chem. B, 106, 6361-6373, 2002.

Jungwirth, P. and Tobias, D. J.: Specific Ion Effects at the Air/Water Interface, Chem. Rev., 106, 1259-1281, 2006.

Kawamura, K., Steinberg, S., Ng, L., and Kaplan, I. R.: Wet deposition of low molecular weight mono- and di-carboxylic acids, aldehydes and inorganic species in Los Angeles, Atmos. Environ., 35, 3917-3926, 2001.

Keppler, J.: Strena seu de nive sexangula, in: A New Years Gift or on the Six-Cornered Snowflake, edited by: Hardie, C., Oxford Press, 24-38, 1966.

Kobayashi, T.: On the Habit of Snow Crystals Artificially Produced, J. Meteorol. Soc. Jpn., Ser. II, 36, 193-208, 1958.

Kobayashi, T.: The Growth of Snow Crystals at Low Supersaturations, Philos. Mag., 6, 1363-1370, 1961.

Kobayashi, T.: Vapour Growth of Ice Crystal between -40 and -90 C, J. Meteorol. Soc. Jpn., 43, 359-367, 1965.

Kuroda, T. and Lacmann, R.: Growth-Kinetics of Ice from the Vapor-Phase and Its Growth Forms, J. Cryst. Growth, 56, 189
205, 1982.

Libbrecht, K. G.: Designer Snowflakes: http://www.its.caltech.edu/ $\sim$ atomic/snowcrystals/designer1/designer1.htm, access: 19 June 2007, 1999.

Libbrecht, K. G.: Morphogenesis on Ice: The Physics of Snow Crystals, Engineering \& Science, 64, 10-19, 2001.

Libbrecht, K. G. and Yu, H.: Crystal growth in the presence of surface melting: supersaturation dependence of the growth of columnar ice crystals, J. Cryst. Growth, 222, 822-831, 2001.

Libbrecht, K. G., Crosby, T., and Swanson, M.: Electrically enhanced free dendrite growth in polar and non-polar systems, J. Cryst. Growth, 240, 241-254, 2002.

Libbrecht, K. G.: California Institute of Technology, Pasadena, CA, Personal Communication, E-mail, 4 June 2005, 2005a.

Libbrecht, K. G.: The physics of snow crystals, Rep. Prog. Phys., 68, 855-895, 2005b.

Liu, D., Ma, G., Levering, L. M., and Allen, H. C.: Vibrational Spectroscopy of Aqueous Sodium Halide Solutions and AirLiquid Interfaces: Observation of Increased Interfacial Depth, J. Phys. Chem. B, 108, 2252-2260, 2004.

Magono, C., Higuchi, K., Orikasa, K., Takahashi, T., Kikuchi, K., Nakamura, T., Kimura, T., and Sakurai, K.: Investigation on the Growth and Distribution of Natural Snow Crystals by the Use of Observation Points Distributed Vertically, III, Journal of the Faculty Science, Hokkaido University, Japan, 1, 373-387, 1962.

Makkonen, L.: Surface melting of ice, J. Phys. Chem. B, 101, 61966200, 1997.

McNeill, V. F., Loerting, T., Geiger, F. M., Trout, B. L., and Molina, M. J.: Hydrogen chloride-induced surface disordering on ice, P. Natl. Acad. Sci. USA, 103, 9422-9427, 2006.

Mucha, M., Frigato, T., Levering, L. M., Allen, H. C., Tobias, D. J., Dang, L. X., and Jungwirth, P.: Unified molecular picture of the surfaces of aqueous acid, base, and salt solutions, J. Phys. Chem. B, 109, 7617-7623, 2005.

Nada, H. and Furukawa, Y.: Anisotropic growth kinetics of ice crystals from water studied by molecular dynamics simulation, J. Cryst. Growth, 169, 587-597, 1996.

Nada, H. and Furukawa, Y.: Anisotropy in molecular-scaled growth kinetics at ice-water interfaces, J. Phys. Chem. B, 101, 61636166, 1997a.

Nada, H. and Furukawa, Y.: Anisotropy in structural phase transitions at ice surfaces: a molecular dynamics study, Appl. Surf. Sci., 121, 445-447, 1997b.

Nakaya, U.: Snow Crystals: Natural and Artificial, 1 ed., Harvard University Press, Cambridge, 510 pp., 1954.

Orlando, J. J. and Tyndall, G. S.: Gas phase UV absorption spectra for peracetic acid, and for acetic acid monomers and dimers, J. Photoch. Photobio., 157, 161-166, 2003.

Perovich, D. K. and Richter-Menge, J. A.: Surface characteristics of lead ice, J. Geophys. Res., 99, 16341-16350, 1994.

Petersen, P., Saykally, R. J., Mucha, M., and Jungwirth, P.: Enhanced Concentration of Polarizable Anions at the Liquid Water Surface: SHG Spectroscopy and MD Simulations of Sodium Thiocyanide, J. Phys. Chem. B, 109, 10915-10921, 2005.

Potter, A. E. and Ritter, H. L.: The Vapor Pressure of Acetic Acid and Acetic-d ${ }_{3}$ Acid-d. The Liquid Density of Acetic-d $d_{3}$ Acid-d, J. Phys. Chem., 58, 1040-1042, 1954.

Rankin, A. M. and Wolff, E. W.: Frost flowers: Implications for tropospheric chemistry and ice core interpretation, J. Geophys. 
Res., 107, 4683-4700, 2002.

Rosenberg, R.: Why is ice slippery?, Physics Today, 58, 50-55, 2005.

Sadtchenko, V. and Ewing, G. E.: Interfacial melting of thin ice films: An infrared study, J. Chem. Phys., 116, 4686-4697, 2002.

Sadtchenko, V., Ewing, G. E., Nutt, D. R., and Stone, A. J.: Instability of ice films, Langmuir, 18, 4632-4636, 2002.

Sadtchenko, V. and Ewing, G. E.: A new approach to the study of interfacial melting of ice: infrared spectroscopy, Can. J. Phys., 81, 333-341, 2003.

Shen, Y. R.: Frank Isakson prize address - Sum frequency generation for vibrational spectroscopy: Applications to water interfaces and films of water and ice, Solid State Communications, 108, 399-406, 1998.

Simpson, W. R., Alvarez-Aviles, L., Douglas, T. A., and Sturm, M.: Halogens in the coastal snow pack near Barrow, Alaska: Evidence for active bromine air-snow chemistry during springtime, Geophys. Res. Lett., 32, L04811, doi:10.1029/2004GL021748, 2005.

Simpson, W. R., Carlson, D., Hönninger, G., Douglas, T. A., Sturm, M., Perovich, D., and Platt, U.: First-year sea-ice contact predicts bromine monoxide $(\mathrm{BrO})$ levels at Barrow, Alaska better than potential frost flower contact, Atmos. Chem. Phys., 7, 621-627, 2007 , http://www.atmos-chem-phys.net/7/621/2007/.

Sokolov, O. and Abbatt, J. P. D.: Adsorption to ice of n-alcohols (ethanol to 1-hexanol), acetic acid, and hexanal, J. Phys. Chem. A, 106, 775-782, 2002.
Stull, D. R.: Vapor Pressure of Pure Substances: Organic Compounds, Ind. Eng. Chem., 39, 517-540, 1947.

Suresh, S. J. and Naik, V. M.: Hydrogen bond thermodynamic properties of water from dielectric constant data, J. Chem. Phys., 113, 9727-9732, 2000.

Takahashi, C. and Mori, M.: Growth of Snow crystals from frozen water droplets, Atmos. Res., 82, 385-290, 2006.

Voss, L. F., Henson, B. F., Wilson, K. R., and Robinson, J. M.: Atmospheric impact of quasiliquid layers on ice surfaces, Geophys. Res. Lett., 32, L07807, doi:10.1029/2004GL022010, 2005.

Vrbka, L. and Jungwirth, P.: Homogeneous freezing of water starts in the subsurface, J. Phys. Chem. B, 110, 18126-18129, 2006.

Wei, X., Miranda, P. B., and Shen, Y. R.: Surface vibrational spectroscopic study of surface melting of ice, Phys. Rev. Lett., 86, 1554-1557, 2001.

Wei, X., Miranda, P. B., Zhang, C., and Shen, Y. R.: Sum-frequency spectroscopic studies of ice interfaces, Phys. Rev. B, 66, 085401, doi:10.1103/PhysRevB.66.085401, 2002.

Wei, X. and Shen, Y. R.: Vibrational spectroscopy of ice interfaces, Appl. Phys. B-Lasers O., 74, 617-620, 2002.

Wettlaufer, J. S.: Impurity Effects in the Premelting of Ice, Phys. Rev. Lett., 82, 2516-2519, 1999.

Wettlaufer, J. S.: Dynamics of Ice Surfaces, Interface Sci., 9, 117129, 2001. 